\title{
ER(+)/HER2(+) and ER-/HER2(+) breast cancers might have different intracranial recurrence patterns after brain-directed radiation for brain metastases
}

\author{
Kadri Altundag ${ }^{1}$ (D)
}

Received: 17 April 2019 / Accepted: 25 April 2019 / Published online: 25 May 2019

(c) Springer Science+Business Media, LLC, part of Springer Nature 2019

\section{Dear Editor,}

I want to congratulate Cagney and their colleagues [1] in which they investigated intracranial recurrence patterns of brain metastases from breast cancer after brain-directed radiation to facilitate subtype-specific management paradigms. They reported a strong association between breast cancer subtype and intracranial recurrence patterns after brain-directed radiation, particularly local progression for HER2+ and distant progression for TNBC patients. However, the authors did not consider ER(+)/HER2(+) and ER-/ HER2(+) as a different subtype. Analysis of HER2+ metastatic breast cancer has often been performed disregarding the ER status of the disease. Recent study examined the metastatic pattern and prognosis of both ER+/HER2+ and ER-/HER2 + 86,093 breast cancer patients [2]. This large study showed that patients with ER+/HER2+ and ER-/HER2 + breast cancers had different metastatic patterns and patients with ER-/HER2+ breast cancer had worse prognosis. Taken all together, ER(+)/HER2(+) and ER-/HER2 $(+)$ breast cancers might have different intracranial recurrence patterns after brain-directed radiation for brain metastases. This issue merits further investigation.
Funding No funding for this paper. Author has not received any grants.

\section{Compliance with ethical standards}

Conflict of interest I have no conflict of interest to declare.

Ethical approval My manuscript complies with the Ethical Rules applicable for this journal.

Research involving human participants and/or animals This article does not contain any studies with human participants or animals performed by any of the authors.

\section{References}

1. Cagney DN, Lamba N, Montoya S, Li P et al (2019) Breast cancer subtype and intracranial recurrence patterns after brain-directed radiation for brain metastases. Breast Cancer Res Treat. https:// doi.org/10.1007/s10549-019-05236-6

2. Arciero CA, Guo Y, Jiang R et al (2019) ER(+)/HER2(+) breast cancer has different metastatic patterns and better survival than ER-/HER2(+) breast cancer. Clin Breast Cancer 1:1-10. https:// doi.org/10.1016/j.clbc.2019.02.001

Publisher's Note Springer Nature remains neutral with regard to jurisdictional claims in published maps and institutional affiliations.

This letter to the editor refers to the article available at https://doi.org/10.1007/s10549-019-05236-6.

Kadri Altundag

altundag66@yahoo.com

1 MKA Breast Cancer Clinic, Tepe Prime, Cankaya, 06800 Ankara, Turkey 